\title{
HUMAN CAPITAL IN ONLINE HIGHER EDUCATION SETTINGS: A SOCIO-EDUCATIVE PERSPECTIVE APPLIED TO GRADUATES OF AN ONLINE UNIVERSITY
}

\author{
Riccardo Valente, Albert Sánchez Gelabert, Josep Ma Duart, Universitat Oberta de Catalunya, \\ Spain
}

\section{Introduction}

In recent decades, a series of changes has shaped a model for universities backing new ways of understanding education and educational institutions in our societies. The appearance of completely online universities and traditional university departments offering online programmes, openly and en masse, bear witness to this. All these changes are an opportunity to rethink the role and function of universities in our increasingly interconnected and global societies. In what follows, we propose our contribution to this debate by focusing on the specific case of the "Universitat Oberta de Catalunya" (UOC), an online university of the Spanish educational system.

The use of technology - particularly the internet - has led to a process of expansion in education and fostered access to higher education for groups historically underrepresented: the working class, older people, ethnic minorities, women with family responsibilities, people with disabilities, etc. The importance of this process of expansion lies in the impacts and benefits of the university and of the increased educational level of the population feeding back to a broad raft of dimensions, at both individual and social levels, and transcending purely economic impacts (Brennan, Durazzi, \& Tanguy, 2013; McMahon, 2010). As noted in a recent study published by Valero and Van Reenen (2016), the economic impact of higher education is not restricted to the investment in personnel and students, but must also be interpreted on the basis of the increase in human capital and a greater propensity for prodemocratic attitudes. More generally, in recent decades, the need to broaden the scope of economic analyses by including elements can help define (and potentially quantify) the social benefits of higher education has received increasing acceptance. In 2017, for example, a report published by the 22 institutions comprising the "League of European Research Universities" (LERU, 2017; p.7) highlighted "the rising demand for universities to explicitly demonstrate (consideration of) societal impact". Against this backdrop, new challenges are being added to universities' classic functions. According to Zgaga (2009), for example, the contemporary model of the university as an institution is characterised by its social dimension: in other words, by its links with the community and the notion of citizenship as core elements. This model involves the incorporation of a broader vision of the benefits of higher education for both students and society at large. Accordingly, this framework requires a wider-ranging 
analysis to evaluate the impact of education beyond the development of knowledge and strictly professional skills.

\section{The Concept of Human Capital}

As Teixeira (2014) notes in his review of Becker's work (1964), the idea that education provides social and economic benefits is not new. Nevertheless, it was only from the 1950s that this supposition became consolidated within the framework of a consistent line of research. In a period of post-war reconstruction, education began to be interpreted as a key resource with a view to the need to boost economic recovery, as can be seen from the proliferation of studies on the matter (Fisher, 1946; Harrod, 1943). It was Becker (1964), in his book "Human Capital", who systematised these prior works and gave structure to one of the first theories on education's impact upon society. According to this author's definition, human capital can be defined as "activities that influence future monetary and psychic income by increasing resources in people" (Becker, 1993; p.11). According to this standpoint, the chief role of educational institutions is associated with their contribution to increasing the level of learning, which, in turn, creates an (economic) impact that affects society as a whole.

Since the publication of "Human Capital" in 1964, most studies on education's impact on society have focused on its ability to create benefits for the economy in terms of productive knowledge-based resources. With regard to higher education, the conclusions of previous literature indicate that the combination of education and training offered by universities fosters a series of benefits in terms of students' greater employability and the quality of their jobs (Blundell, Dearden, Goodman, \& Reed, 1997), or higher salaries (Carnoy et al., 2012), which, in the end, has an impact upon the economy as a whole via final consumption expenditure.

Turning to the specific case of this study and the specific features of online universities, impact studies note, firstly, the flexibility of the courses offered and the benefits in terms of accessibility for certain groups (adults with family responsibilities, full-time workers, the disabled, etc.) (UNESCO, 2002). Additionally, given their characteristics, these students' profiles differ from those of their fellow-students at face-to-face universities with regard to their motivations. As shown by the results of the IDEAL project (2013-2015), carried out across five European counties (Germany, Finland, Greece, Hungary and the United Kingdom), the main factors influencing the choice of online university are associated with the aspiration to improve theoretical knowledge, career consolidation and improving future employment prospects.

On the other hand, with his concept of "externalities", McMahon (2009) is regarded as making the first attempt to formulate a theory specifically designed to estimate the spillover effects of (higher) education on society as a whole. Externalities are social benefits spilling over into society and future generations, as the result of the mediating role of the human capital transmitted by universities to their students. Additionally, this author's work points to a difference between private benefits, in terms of the monetisation of the skills acquired when 
studying, and the social benefits, such as the fostering of democratic attitudes, and greater awareness of civic engagement which, although indirect, have a substantial impact on a social level. From this author's perspective, then, higher education is a "public asset" in that it contributes to a better quality of life. Other research has provided evidence regarding the role of education in developing active citizenship, i.e., the learning of participatory attitudes, social justice values, citizenship values, and cognition about democratic institutions (Hoskins, D'Hombres, \& Campbell, 2008). Within the context of Catalonia, studies show the same patterns, with the population with higher education levels showing greater participation, political engagement and volunteering, as well as individual electoral participation and likelihood of voting (Soler-í-Martí, 2011). In this same regard, Anduiza, Cantijoch, and Gallego (2009) note the importance of the level of education with regard to new forms of participation in online contexts and to the differences in forms of participation, be they institutional or extra-institutional (protests, political consumption or expressive participation). Nevertheless, it should be noted that although these democratic externalities are associated with a higher level of education, the relationship is not linear. In the exclusive case of university students and their participation in the institution's bodies, there are differences depending upon the type of university. Specifically, online university students place less importance on the different forms of participation than their peers in face-to-face ones (Laker, Naval, \& Mrnjaus, 2014).

\section{Objectives}

The analysis that follows is based upon a multidimensional definition of human capital that is not limited to the creation of added value or increased salaries arising from a boost in skills prized on the job market. Instead, the objective consists in testing a construct oriented towards an updated definition of human capital (Becker, 1964) that could encompass the spill over effects upon society as a whole (McMahon, 2009). Additionally, given the specificities of the case study (an online university), particular emphasis has been placed on the role of higher education in fostering an improvement in digital skills and a consolidation of career prospects. To empirically test the proposed theoretical model, confirmatory factor analysis was performed. Based on the outputs of the factor structure, a series of ad hoc nonparametric tests were implemented to check for the existence of potential differences based on the characteristics of the graduates.

\section{Methodological Approach}

The data collection method (a questionnaire) is the result of a process of updating an earlier version used in a study published in 2009 by Carnoy et al. (2012) and designed to identify potential salary increases and/or improvements in job quality for former students. This updated version includes a series of items for which students assess the benefits on digital skill levels and in the social sphere (greater social responsibility, greater participation, etc.) derived from their enrolment at the UOC. The construct labelled human capital involved four latent factors: 
1. Firstly, learning, which represents a classic dimension of a university's role in society. To measure the impact in terms of learning, we included a raft of questions by means of which respondents could score on a scale from 1 (no impact) to 5 (maximum impact) the UOC's role in the transference of new concepts, personal development (self-affirmation, self-discipline, etc.) and the incorporation of an interdisciplinary and crosscutting vision.

2. Secondly, socio-political awareness: defined as the development of pro-social attitudes promoting participation in society. Respondents were asked to specify their degree of agreement with three statements of the role of their studies at the UOC in establishing a greater social engagement, civic and social responsibility and political participation. The measurement scale consisted of five points, with low values indicating positions of disagreement and higher values, greater agreement.

3. Thirdly, digital skills, which constitute a particular aspect of academic contexts in which activities are performed in virtual and online environments. Account was taken of a list of five online skills: the search for and access to information on the Internet, task planning in virtual environments, the creation of digital content in different formats, the ability to guarantee one's own online security and personal data protection, and the identification and resolution of technical problems. The question included in the survey was as follows: "Thinking of before and after your entry into the UOC, we would ask you to rate from 1 to 5 , where 1 is a novice level and 5 an expert level, your user level with regard to the digital skills listed below". Formulated in this way, the question permitted the quantification of potential improvements in digital skills by calculating the difference between the initial level and that after obtaining the qualification.

4. Lastly, we included a focus on career consolidation and the impact upon employment. Respondents were asked to self-assess the impact of their studies at the UOC in terms of the incorporation of new concepts that were useful in the workplace and of improvements in working conditions, on a scale from 1 to 5 (no impact vs. maximum impact).

Table 1: Description of data

\begin{tabular}{|c|c|c|c|}
\hline Dimensions & Variables & Mean & SD \\
\hline \multirow{3}{*}{ Learning } & Incorporation of new concepts & 3.92 & 1.047 \\
\hline & Self-affirmation and self-discipline & 3.76 & 1.164 \\
\hline & Interdisciplinary and crosscutting vision & 3.53 & 1.189 \\
\hline \multirow{3}{*}{$\begin{array}{l}\text { Socio-political } \\
\text { awareness }\end{array}$} & Social engagement & 2.37 & 1.224 \\
\hline & Political participation & 2.42 & 1.214 \\
\hline & Civic and social responsibility & 2.62 & 1.229 \\
\hline \multirow{5}{*}{ Digital skills } & Search for and access to information on the internet & 1.15 & 1.138 \\
\hline & Task planning in virtual environments & 1.42 & 1.190 \\
\hline & Digital content creation & 1.07 & 1.054 \\
\hline & Online security & .72 & .991 \\
\hline & Problem solving & .80 & .955 \\
\hline Career & Improving my working conditions & 2.32 & 1.365 \\
\hline consolidation & Practical job-related knowledge & 3.12 & 1.330 \\
\hline
\end{tabular}




\section{Instrument Validation and Survey Administration}

After conclusion of the design phase, the questionnaire was subjected to expert validation. Subsequently, a pilot test was implemented for nine days between 25 September and 3 October 2018, involving a sample of 150 subjects. The final version of the survey was administered online. Potential participants were contacted in advance by email, informing them of the study's nature and objectives. The email included a link to access the consent form for processing personal data. Respondents' explicit consent was sine qua non for their participation in the survey. The web platform used to administer the survey was Qualtrics (www.qualtrics.com). Emails were sent on 22 October, 2018, at 12:00, and the survey was closed at the same time on 9 November, 2018. A reminder was sent on 29 October.

\section{Statistical Processing of the Data}

Initially, we analysed the basic characteristics of the available data (frequency distribution, contingency tables and percentages). Subsequently, we opted for confirmatory factor analysis, as it was regarded as the most suitable technique for proposing a statistically validated conceptualisation of the possible increases in human capital among the UOC's graduates. To examine the reliability and internal consistency of the components, the coefficients of the composite reliability index were calculated, as was the average variance extracted. Based on the results of the confirmatory factor analysis, a "self-estimated human capital index" was calculated on the basis of the weighted sum of the factor scores making up the factor structure. The factor scores were used to implement the nonparametric tests Kruskal-Wallis and Mann-Whitney $\mathrm{U}$, depending upon the type of variable to be analysed (ordinal or dichotomous, respectively). Interpretation of the tests' $p$ values permitted verification of the potential existence of statistically significant differences based on demographic features (sex and age), the state of psycho-physical health, the number of years since graduation and the level of the studies completed (undergraduate or postgraduate) by alumni.

\section{Results}

\section{Description of the Sample}

The 18 days of data collection meant it was possible to reach a sample size of 2,869 subjects, $55 \%$ of whom were women and $45 \%$ men. The average age of respondents was 44 . With regard to nationality, $93 \%$ were Spanish. $70 \%$ of the sample was resident in Catalonia, $22 \%$ in another Spanish Autonomous Community and 8\% from outside Spain. Two-thirds of respondents lived with a partner at the time of entering the UOC, whether with children $(32 \%)$ or without (31\%). The third-most common family situation, in decreasing order, was childless singles, at $29 \%$, as well as $1.4 \%$ single parents. Less frequent were those separated $(5.6 \%)$ or widowed $(0.5 \%)$, or with a status other than the aforementioned (1.5\%). In terms of family background, $8 \%$ of fathers and $10 \%$ of mothers of UOC graduates have no qualifications, and $30 \%$ and $36 \%$, respectively, only received primary education. These figures coincide with previous surveys conducted by other bodies (see for example, AQU Catalunya, 
2017) whose conclusions indicate that, in comparison with graduates of other Catalan universities, those of the UOC come from families with a lower educational level (in terms of formal education). $91 \%$ of respondents were working when they entered the UOC. The remaining $9 \%$ stated they were unemployed $(5.3 \%)$, retired $(0.7 \%)$ or in another unspecified situation (3\%). Additionally, 54\% stated that the studies they followed at the UOC were associated with their job, against the $46 \%$ who declared that they were not. With regard to the level of the studies, 70\% followed an undergraduate course, while the remaining 30\% enrolled for a master's or a doctorate. On average, respondents had ceased studying at the UOC 2.4 years previously (around 29 months). The graduates making up the sample were characterised by a certain degree of job stability, as, at the time of the survey, $89 \%$ were working, predominantly in public administration or in the field of information and communication technology.

\section{Validation of an Updated Construct of Human Capital applied to HE in online settings}

To estimate the factor structure, we chose the weighted least square mean and variance adjusted (WLSMV) model, which is regarded as the most suitable with categorical variables. According to the goodness of fit statistics, the model shows a highly satisfactory fit. The $\mathrm{x}^{2} / \mathrm{df}$ ratio is 4.9 , the comparative fit (CFI) and Tucker-Lewis (TLI) indices showed values above the cut-off $(\geq .95)$, while the root mean square error of approximation (RMSEA) stood at .039. Interpretation of the factor loading values confirms the existence of strong and statistically significant relations between the variables and factors. Also, the calculations of the internal reliability index $(\mathrm{CR} \geq .60)$ and the average variance extracted $(\mathrm{AVE} \geq .50)$ support results pointing to a solid factor structure with good internal consistency. Interpretation of the model's standardised coefficients suggests that all the factors make a significant contribution to the model. Both learning $(\beta=.87 ; p<.001)$ and socio-political awareness $(\beta=.67 ; p<.001)$ contribute significantly. Moreover, the factor associated with skills fostering career consolidation $(\beta=.69 ; p<.001)$ identifies one of the dimensions peculiar to the UOC as a professionalising university that attracts the profile of a student/worker whose motivations for studying are related to the need to improve their working conditions. Lastly, the results indicate that progress in terms of digital skills $(\beta=.51 ; p<.001)$ has significant weight in the self-estimation of human capital on the grouping analysed.

\section{Differences Between Profiles}

Given the promising results obtained through the implementation of confirmatory factor analysis, we decided to explore the likelihood of the existence of differences in terms of perceived impact depending upon the respondents' characteristics and life conditions. A preliminary step was to calculate a value that could summarise the proportional contribution of each factor to the factor structure. To do this, after obtaining the factor scores using the regression method (regression scores), their proportional value was calculated on the basis of the $\beta$ value emerging from the outputs of the previous factor analysis. The sum of the proportional $\beta$ factors for each latent factor provides a final value we have called the "self- 


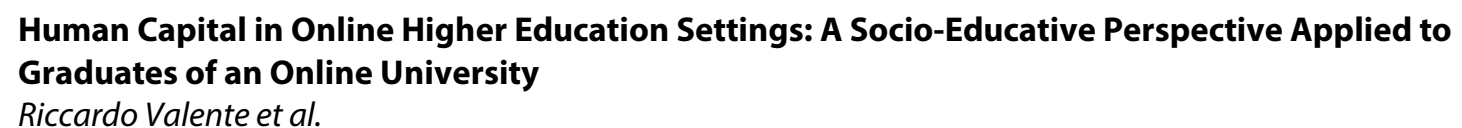

estimated human capital index". Two nonparametric tests (Kruskal-Wallis and MannWhitney's U) were then applied using the following grouping variables: sex, age ranges, presence or absence of health problems during studies, years since obtaining qualification (as an ordinal variable), and level of studies completed at the UOC (undergraduate or postgraduate). Additionally, the variables to be compared were the first-order latent factors (learning, socio-political awareness, career consolidation and digital skills).

Initially, it is worth highlighting that no statistically significant differences were found between men and women, with the sole exception of the latent factor identifying the benefits in terms of career consolidation. In this particular case, the difference is significant $(p<.05)$ and the mean rank value is greater among men, which points to a greater propensity for this grouping to consider that their studies have had a positive impact upon their careers. The same tendency is seen when it comes to comparing respondents stating that they had experienced health problems during their studies with those that did not. Again, in this case, the significant difference $(p<.01)$ and the mean rank are greater among those who did not experience any health problems. In both cases, one could make the hypothesis that the emphasis on career consolidation depends, to a great extent, on a better and more consolidated position on the job market for men and for those not suffering from health problems, compared with women and graduates whose academic performance was negatively affected by health problems.

Age differences are significant for all analysis levels taken into account. At a first level, it was noted that self-estimation of impact increased among respondents in the age ranges 36-50 and over 51 (i.e., that adult graduates perceive the greatest benefits). Looking in detail at each of the first-order latent factors, this tendency is consolidated if one considers, for example, that the average range values associated with improvements in digital skills and socio-political awareness are higher in these two age ranges. On the other hand, it is the young who perceive more benefits in terms of learning (in its more traditional definition as the acquisition and consolidation of knowledge), and career consolidation, which takes on especial importance considering that they are at a stage of their lives in which career consolidation is a key factor.

Significant differences also emerge if we consider the number of years that have passed since obtaining the qualification. In this case, the tendency is unmistakable and in the expected direction: the more years that have passed since graduation, the more the perception of benefits diminishes. However, one significant exception was recorded, with regard to the factor associated with learning. The results indicate that the benefits in this sense become more tangible with the passing of time (from three years and more after completing the studies).

Lastly, we explored the differences arising from the level of studies followed. Although no differences were found in terms of learning, the Mann-Whitney $U$ test shows that the perceived benefits in digital skills and career consolidation are more evident with master's 
and $\mathrm{PhD}$ students. Additionally, the levels of socio-political awareness are proportionally greater among postgraduate students.

\section{Conclusions}

This paper contributes to literature presenting a statistically validated definition of human capital including factors associated with learning, civic education, digital skills and career consolidation. Additionally, it found that the principle means of differentiating between graduates' profiles was time-based, in the dual sense of their age and the number of years since they had obtained their qualification. Specifically, the (perceived) benefits are greater in age ranges from 36 years and up, backing the intuition regarding the UOC's contribution to lifelong learning processes. However, the perceived benefits progressively diminish with an increase in the number of years that have passed since leaving the university. Lastly, the impacts in terms of theoretical and/or practical skills valued on the job market are clearer among respondents who are at a time of their lives in which they have just entered the job market and need to consolidate their position there.

\section{References}

AQU Catalunya (2017). Enquesta d'inserció laboral. Barcelona: Agencia per a la Qualitat del Sistema Universitari de Catalunya.

Becker, G. (1964). Human Capital. New York: Columbia University Press.

Becker, G. (1993). The economic way of looking at behavior. Journal of Political Economy, 101(3), 385-409.

Blundell, R., Dearden, L., Goodman, A., \& Reed, H. (1997). Higher Education, Employment and Earnings in Britain. London: Institute for Fiscal Studies.

Brennan, J., Durazzi, N., \& Tanguy, S. (2013). Things we know and don't know about the Wider Benefits of Higher Education: A review of the recent literature.

Carnoy, M., Rabling, B., Castano-Munoz, J., Duart Montoliu, J. M., \& Sancho-Vinuesa, T. (2012). Does Online Distance Higher Education Pay Off for Adult Learners? The Case of the Open University of Catalonia. Higher Education Quarterly, 66(3), 248-271.

Fisher, A. (1946). Education and Economic Change. South Australia: W.E.A. Press.

Harrod, R. (1943). Full employment and security of livelihood. The Economic Journal, 53(212), 321-342.

Hoskins, B., D’Hombres, B., \& Campbell, J. (2008). Does Formal Education Have an Impact on Active Citizenship Behaviour? European Educational Research Journal, 7(3), 386-402.

IDEAL (2013-2015). Impact of Distance Education on Adult Learning. Project number: 539668-LLP-1-2013-1-NO-ERASMUS-ESIN.

Laker, J., Naval, C., \& Mrnjaus, K. (2014). Citizenship, Democracy and Higher Education in Europe, Canada and the USA. London: Palgrave Macmillan. 
LERU (2017). Productive interactions: societal impact of academic research in the knowledge society. Retrieved from https://www.leru.org/files/Productive-Interactions-SocietalImpact-of-Academic-Research-in-the-Knowledge-Society-Full-paper.pdf

McMahon, W. (2009). Higher Learning, Greater Good. The Private and Social Benefits of Higher Education. Baltimore: The Johns Hopkins University Press.

McMahon, W. (2010). The private and social benefits of Higher Education: the evidence, their value, and policy implications. TIAA-CREF Institute.

Soler-i-Martí, R. (2011). Democràcia, participació i joventut. Barcelona: Departament de Benestar Social i Família.

Teixeira, P. (2014). Gary Becker's early work on human capital - collaborations and distinctiveness. IZA Journal of Labor Economics, 3(12), 1-20.

UNESCO (2002). Open and Distance Learning. Trends Policy and Strategy Considerations. Retrieved from http://unesdoc.unesco.org/images/0012/001284/128463e.pdf

Valero, A., \& Van Reenen, J. (2016). The Economic Impact of Universities: Evidence from Across the Globe. Retrieved from https://www.nber.org/papers/w22501

Zgaga, P. (2009). Higher education and citizenship: “The full range of purposes.” European Educational Research Journal, 8(2), 175-188. https://doi.org/10.2304/eerj.2009.8.2.175 